\title{
Digging a Hole at Diamond Realty
}

\author{
Lisa Formato \\ Long Island University \\ Barry Armandi \\ SUNY-Old Westbury \\ Herbert Sherman \\ LIU- Southampton College
}

\begin{abstract}
This case centers on the Director of Human Resources research into a $\$ 45,000$ shipment from Bathes Inc., a supplier of bathroom fixtures and accessories that had unexpectedly come to the office. Her preliminary research uncovered an embezzlement scheme between four related employees to move corporate funds into private accounts as well as to purchase goods and services on corporate credit cards. A private investigator uncovered the details of the scheme as well as major home improvements made to certain suspects' homes that could not be connected to personal credit card charges, loans/credit lines, or withdrawals from bank accounts. Part A of the case end's with the Director's presentation of the findings to the CEO who breaks down and cries. In Part B of the case we find out that no action has been taken by the firm, the embezzling employees continue to accrue wealth at the company's expense, and the firm has ironically hired two more of the suspects' family members.
\end{abstract}

\section{Digging a Hole at Diamond Realty* Part A}

"How could this happen," sobbed Conrad Jefferson, CEO and founder of Diamond Realty. "I trusted these people and this is how I get treated? Why did they do this to the Company and me? I should fire them immediately. Or is there something else I should do?"

\section{Background}

Diamond Realty, a publicly traded real estate investment trust, owned and operated the nation's largest portfolio of neighborhood and community shopping centers (measured by gross leaseable area). Diamond had interests in 495 properties comprising approximately 66.5 million square feet of leaseable area in 41 states.

Since its incorporation in 1966, the Company specialized in the acquisition, development, and management of strategically located centers with strong growth potential. Self-administered and self-managed, the Company focused on increasing the 
cash flow and enhancing the value of its shopping center properties through strategic re-tenanting (replacing old tenants with new ones as soon as lease terminations are announced), redevelopment, renovation and expansion. The Company achieved dramatic growth through selective acquisitions of neighborhood and community shopping centers that had below market-rate leases or other potential cash flow growth.

The Company's common shares were traded on the New York Stock Exchange. Some financial information follows.

In 2002, funds from operations increased $14.8 \%$ to $\$ 254.1$ million from $\$ 221.4$ million. Net income increased $16.0 \%$ to $\$ 205.0$ million from $\$ 176.8$ million. Funds from operations per diluted common share increased $11.6 \%$ to $\$ 4.03$ from $\$ 3.61$. Net income Per Diluted Common Share increased $16.3 \%$ to $\$ 2.86$ from $\$ 2.46$. Annual dividends paid per common share increased $12.2 \%$ to $\$ 2.66$ from $\$ 2.37$.

The main headquarters of the office was located in Queens, New York and consisted of about 250 people. There were 13 regional offices across the country. The department represented within this case was the Financial Operations Department (see Appendix A for the organizational chart).

\section{Something is Rotten}

In February of 2003, Mary the receptionist received a phone call concerning a delivery of expensive products to the office. During the conversation, she discovered that a $\$ 45,000$ shipment from Bathes Inc., a supplier of bathroom fixtures and accessories, was expected to come to the office and someone needed to sign for it at the front desk. Since this was highly unusual, Mary was unaware of what to do so she forwarded the call to the Human Resource Department. Kitty, the Director of Human Resources, received the call from reception. After speaking with Mary, Kitty found that the items were purchased on a corporate credit card and were to be delivered that day. There were no names attached to the order. Usually the mailroom received shipments and Allan or Earl would sign for them, and then have them delivered to the department or person. Kitty felt this was odd. She held up the order and began doing some research. After speaking with a number of people, including the vendor, she began to piece together an intriguing process.

\section{The Hole Gets Dug}

Allan Herald was hired as a mailroom clerk in 1995. Over time he became the mailroom coordinator. Allan was responsible for the distribution of interoffice mail, out going mail, and incoming mail. He was also responsible for all of the Company's banking deposits on a daily basis.

Earl Herald, Allan's older brother, started with the company in 1999. He also worked in the mailroom as a clerk. Earl alternated with Allan on the daily deposits for the Company. 
John Moses, Allan's first cousin, was hired to work in the Management Information Systems Department in 1999. He was responsible for solving employee computer problems, and for helping with computer programs and Internet access. As an MIS technician John could fix anyone's computer anytime from his personal computer. He simply would sign on as one of the employees and would work as if he was at that employee's computer station. To do this, John had access to every employee's password and PC at anytime of the day. In addition, John monitored daily usage of the Internet by employees from his workstation.

John devised a scheme in which he monitored usage of the Internet and used the corporate credit card number for his personal use. John told Allan about the possible use of the credit card. Allan seized upon the idea and ordered some items for the remodeling of his home. Had it not been that Allan made it public knowledge about his remodeling, nor for the mistaken vendor delivery call, the scheme would have gone undetected. Obviously, the vendor made a mistake in the delivery. Rather than sending the merchandise to the mailroom, the vendor sent it to the reception area. In speaking with the vendor, Kitty learned that a new employee of the vendor made the mistake. The vendor was very apologetic.

Kitty continued her extensive research. She did a thorough investigation on Allan and his family. She examined their daily functions and responsibilities. Unfortunately, the research was becoming too time consuming. Kitty approached her manager, the Chief Operations Officer (COO), and made him aware of the situation. The $\mathrm{COO}$ set up a meeting with the Chief Financial Officer and the Vice President of Financial Operations. They advised her to hire a private investigator, who would provide objective information of the employees in question.

\section{The Investigator's Report}

A private agency was engaged and began an exhaustive investigation of those suspected. After two weeks, the investigator had sufficient information to understand the scheme. The following findings were reported to Kitty:

- Every day, taking turns, Earl and Allan stopped by a post office box in the middle of the night. They picked up a bag of mail and brought it to Earl's home, which was closer than Allan's house.

- Allan's house recently was fully renovated. Included was a new roof, new siding, new kitchen, new bathroom with a Jacuzzi, and a new concrete driveway.

- Allan's credit cards had no significant charges over the last year for any of the improvements performed on the house. The assumption was that only cash was paid to contractors or laborers. 
- Kitty informed the investigator that the corporation's express mail provider changed from FedEx to UPS back to FedEx in a year and a half's time. The investigator then discovered that the UPS account manager for Diamond Realty, and other corporations he was managing, was accused of smuggling drugs with Allan to and from other countries. No charges were filed against Allan.

- The private investigator also learned that the post office box was registered to a fictitious person with a signature that identically matched Allan's. After obtaining written permission from Kitty, the investigator viewed the contents of the post office box. He discovered that the box was full of checks, each for a different amount, made out to different vendors, companies, and people. After further research, he found that most of these companies and people were fictitious. The checks ranged from $\$ 5.35$ to $\$ 10,000$ with some being duplicates, but were cut from different Diamond Realty bank accounts.

With the help of some accounting clerks, Kitty checked out the financial information. She never informed the clerks as to why she was working with all these vendors, but rather that there was a "glitch" in the system that needed to be corrected. The clerks and Kitty discovered the following:

The mailroom clerk (either Allan or Earl) was responsible to pick up all the deposit slips for newly opened bank accounts. An account could be opened by telephone. Deposit slips were picked up in person. Since the monthly bank statements were mailed to the Corporation, Allan or Earl opened and delivered all the mail. Deposits were made to that company's account. The company was fictitious and created by Allan. Earl or Allan made deposits, and since no one was aware of this, the account could be closed at any time. The bank check Allan received from closing an account would be made to that fictitious company. He would cash the check at the same bank and deposit it into his own personal account.

Also, Allan created fake vendors and fake invoices and had Diamond Realty checks paid to those vendors mailed to a post office box. Not to arouse suspicion, most checks were cut to a vendor only once and in small amounts (under \$100) that hardly were ever examined. For example, assume 10-15 phony corporate accounts were created to deposit the checks. Allan would have a small number of checks (one or two) or a larger number (from forty to fifty) per week arriving at the post office box. These checks were from Diamond realty payable to the phony vendors. Then Allan would deposit the checks in the phony bank accounts. Endorsement of the checks was made with a stamp. The checks were deposited and cleared, the money withdrawn, and eventually the account closed.

Next, the accounting clerks and kitty did vendor research. Kitty inquired as to how did vendors get entered into the accounting system and who approved them? The process was that Accounts Payable created vendors in the system after a request was formally (in writing) applied for with all the proper information. Required information for a request was name, address, Federal Employer Identification number, and a signature from a manager. All approved requests were entered by Alberta. 
Alberta Johnson started with the company in 1994 in the file room, which was part of the mailroom. Since she was there before Allan, she trained him on the file systems. She left the file room to become the corporation's full time receptionist. After a year, she became the assistant to Ellen Houlihan, manager of Accounts Payable. Ellen was with the Company since 1987 and was responsible for all payments on bills, mortgages, and vendor invoices. She was at one point the only person running the Account Payables Department. In 2001 Ellen died of cancer. Within 2 months after her death, Alberta was promoted and a new accounting system was created.

Because Allan and Alberta were friends, Alberta didn't question any vendor request forms that came from Allan. Alberta "let it slide" if the proper information and signatures were not presented. Since Alberta was the Accounts Payable Supervisor, she had the authority to delete vendors and their past activity (e.g. checks previously written out) if necessary or if she desired.

Alberta spent hours working on the "in's and out's" of the new system helping to perfect it for Diamond Realty. With Alberta being the only individual in her department with full knowledge of the Accounts Payable system, she trained all her subordinates.

Therefore, based on her expertise of the system, no one questioned Alberta.

Kitty further discovered that since Alberta became supervisor, checks were mailed to the post office box. The probability of her involvement was quite high. It was common knowledge that Alberta just took a long honeymoon vacation in Fiji, threw an expensive wedding, and bought a new home.

Once Kitty had all of this information she was confident that Allan, Earl, John, and Alberta were accomplices in this matter. She quickly updated the $\mathrm{COO}$ with the facts, who advised her to go to the CEO, Conrad.

\section{The Meeting with Conrad}

Kitty entered Conrad's office. Conrad, a jolly friendly man, was CEO and founded the company back in the 1950's. Well over eighty years old, he was one of the richest men in real estate in the country. He was sitting in his oversized leather chair while on the phone and had no idea what was coming. Kitty sat down and started to tell him about the call which led to the investigation. She gave him the step-by-step account of the investigator's and her clerk's findings. She informed him of all who were involved in the scheme. The CEO took a deep breath, shook his head, and began to cry! 


\section{Appendix A \\ Organization Chart for Diamond Realty \\ Financial Operations Department \\ 2002}

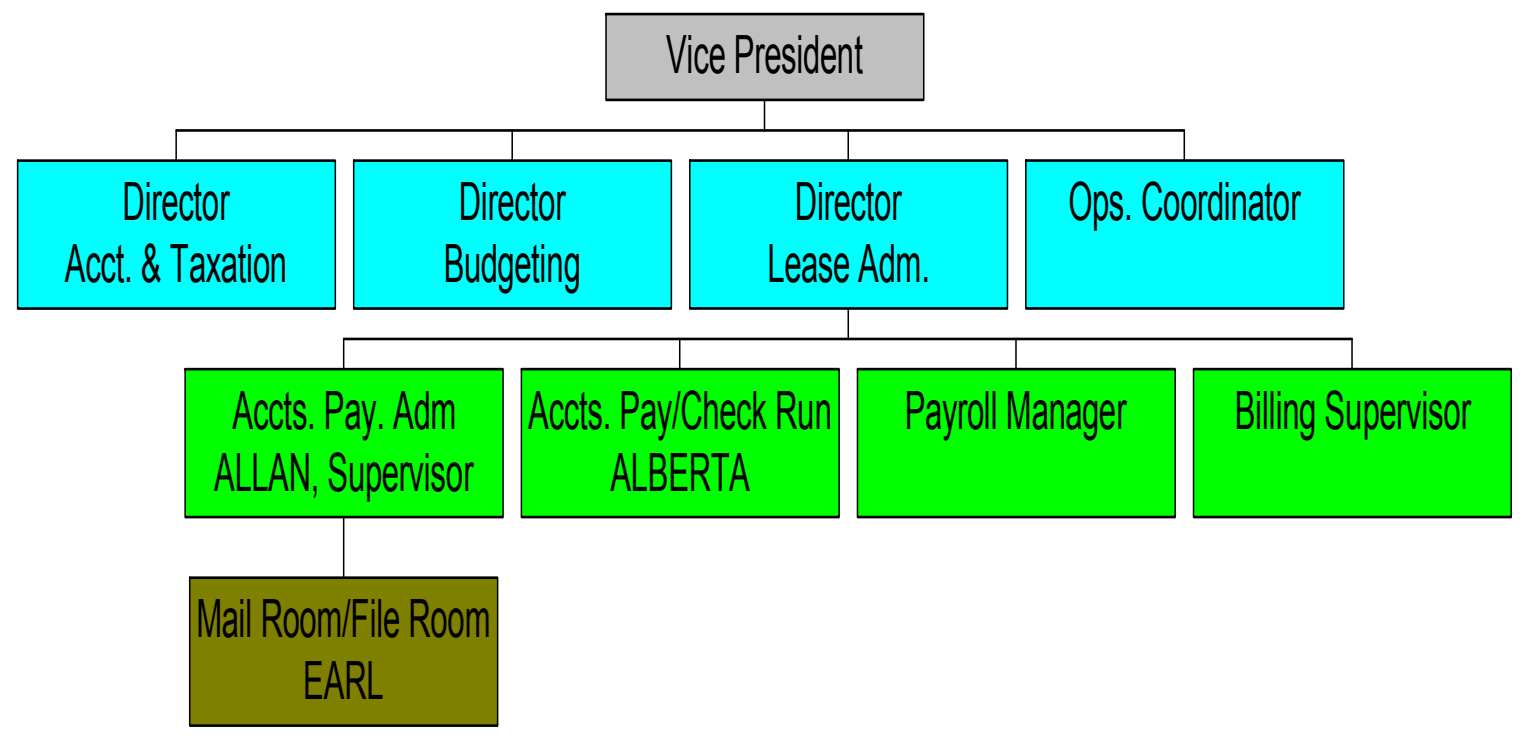




\section{Digging a Hole at Diamond Realty \\ Part B}

As of January 2003, there was enough evidence to arrest Allan on embezzlement and credit card fraud. However, since Allan and other's actions were so complex, the magnitude of the embezzlement was uncertain. Like wise, the monetary extent of the damages was difficult to compute. Further, Conrad feared having Allan and his cohorts fired since he believed that the firm would never get the information about the embezzled funds. The employees in question remained employed, were never warned, and the private investigator was still working on the case.

In the mean time, Allan and his wife announced that Allan graduated from college and hoped to obtain a new position at Diamond in the Accounting Department. However, if the Company did not "promote" him from the mailroom, Allan and his wife will move to Florida into a brand new house they purchased. When asked, Allan's wife was very sure of the move, while Allan shrugged his shoulders and said that he was staying.

Earl was still working in the mailroom. And John bought a house worth over a half a million dollars in an affluent neighborhood. Both Allan and John were in a private college that was paid for by the Company. Their tuition ( $\$ 9,500$ each per semester) was more than anyone ever received in the Company and greatly exceeded the corporate limit of $\$ 6,000$ total per person.

Allan requested more help in the mailroom, which was subsequently approved by Conrad. Allan was given the authority to hire whomever he wanted. He convinced the Vice President that for "continuity" and "diversity", two family members should be hired. Dario (17 years old) was Allan's nephew and Jack (27 years old) was John's little brother. They worked 40 hours a week, did not graduate from high school, and had absolutely no experience. They grossed anywhere from $\$ 700-\$ 1000$ per week.

${ }^{*}$ All events are true. Names have been changed to provide confidentiality. For a detailed teaching note contact Barry Armandi. 